\title{
Regional disparities in the distribution of Sudan's health resources
}

Mohamed Ismail ${ }^{1}$

'Institute of Public Administration, Riyadh, Saudi Arabia (Correspondence to: Mohamed Ismail: ismailm@ipa.edu.sa).

\begin{abstract}
Background: Equal distribution of health resources has been a core objective of both long- and medium-term strategic plans for the health sector in Sudan. However, the targets of these plans have not yet been achieved, resulting in weak performance of the whole health system. The unequal distribution of the health resources has resulted in significant regional disparities in provision of health care services.
\end{abstract}

Aims: This study aims to describe and analyse the inequality in geographic distribution of public sector's physical and human health resources in Sudan. In addition, the study also aims to measure the relations between density of health resources and health outcomes.

Methods: State-level data on health resources and health outcomes obtained from the Sudan Health Statistical Report of 2016 were used to calculate inequality indices, drawing Lorenz curves, and calculating Spearman's correlation analysis between health resource density and health-related outcomes.

Results: Our findings show that the distributions of health resources, based on population size, were highly unequal among the 18 states of Sudan.

Conclusion: There is a crucial need to improve health status in the relatively under-resourced states, particularly in Darfur, South Kordofan and Blue Nile states. Moreover, the government needs to use health resource allocation models that take into account the population size and health outcomes variables in each state in future health strategies.

Keywords: health resources, Gini coefficient, dissimilarity index, resource concentration index, Sudan

Citation: Ismail M. Regional disparities in the distribution of Sudan's health resources. East Mediterr Health J. 2020;26(9):1105-1114. https://doi. org/10.26719/emhj.20.056

Received: 09/02/19; accepted: 04/06/19

Copyright (C) World Health Organization (WHO) 2020. Open Access. Some rights reserved. This work is available under the CC BY-NC-SA 3.0 IGO

license (https://creativecommons.org/licenses/by-nc-sa/3.o/igo)

\section{Introduction}

\section{Background}

Inequality of health resources is a worldwide phenomenon but it is more predominant in developing countries (1). Maldistribution of health resources has been one of the leading health care problems in many countries (2). Several studies have shown that inequitable geographical distribution of health resources is a major problem that hinders population access to health care services (35). Moreover, many studies show that there is a positive correlation between the availability of health resources and health outcomes represented by life expectancy and mortality rates $(6,7)$. Therefore, equitable distribution of health resources in developing countries is of paramount importance, as many of these countries face severe shortages in physical and human resources to provide essential health care services $(8,9)$.

In Sudan, inequitable regional distribution of wealth and resources has been the leading driver of political conflicts and violence since its independence in 1956 (9-11). Power sharing, equal distribution of national resources and provision of basic services to all citizens have been the main common goals for both political parties and armed movements (11). Many factors have cumulatively contributed to the inequality of resources in Sudan in the past decades. These factors include political, economic and administrative polices adopted by the successive national governments (10).

Nonetheless, the government of Sudan strives to provide equitable health care services to the whole population. The long-term strategic plan for health sector (2003-2027) aims to provide equitable, accessible, affordable, efficient and quality health care services (12). In line with the long-term plan objectives, the national health sector medium-term plan (2012-2016) also marks equity in access and utilization of health services (13). However, the targets of these plans have not been achieved (14). As a result, the distributions of health resources have been highly unequal, reflecting significant regional disparities in provision of health care services (13-15). For example, recent statistics show that the number of physicians per 100,000 population varied between 1.8 and 28.5 physicians across the Sudan's 18 administrative states in 2016 (16). The range is even wider for the nurse density rate, ranging from 6.6 to 90.2 nurses per 100000 population (16).

Thus, it is immensely important to carry out research on the inequality of geographic distribution of health care resources in Sudan to enable the country to set strategies for improving population access to health care services.

\section{Sudan's health status}

The key national health indicators reveal that the overall Sudan's health status is low $(8,17)$. Moreover, the point es- 
timators of these indices disguise significant interstate and intrastate differences. There are marked disparities in the values of these indicators between the country's states. For example, the percent of the population with no access to health services ranged between 20 to $40 \%(8)$. This is mainly due to security concerns in conflict-affected states in Darfur, South Kordofan and Blue Nile, where most health care facilities are not accessible (8). About $45 \%$ of the population has no access to improved drinking water, particularly in the rural and conflict-affected areas, and more than $50 \%$ of selected essential medicines are not available (17). Moreover, the physician, nurse, and midwife densities are far below the minimum threshold of 230 doctors, nurses and midwives per 100000 population that was recommended by WHO as necessary to deliver crucial maternal and child health services (18).

Despite the poor health status, the infant mortality rate (IMR) fell from 70 per 1000 live births in 2006 to 48 per 1000 live births in 2015, but still higher than the Millennium Development Goals (MDGs) target of 40 deaths per 1000 live births $(17,19)$. Similarly, the under-5 years mortality rate (U5MR) also declined from 112.2 per 1000 live births in 2006 to 70 per 1000 live births in 2015, again still higher than the MDGs target of 53 deaths per 1000 live births in 2015 (17,19). Likewise, the maternal mortality rate (MMR) decreased from 509 per 100000 live births in 2000 to 311 per 100000 live births in 2015, still higher than the MDGs target of 134 deaths per 100000 live births $(17,19)$. The total life expectancy at birth also improved, from 58.0 years in 2007 to 63.7 years in $2015(17,19)$.

This poor status of health is largely associated with low financial and human resources allocated to the health sector. In Sudan, the domestic general government health expenditure is extremely low, amounting to less than $2 \%$ of the Gross Domestic Product (GDP) in 2015, far below the world level (20).The per capita government and private health expenditures in in 2015 were PPP US\$ 86.3 and PPP US\$185.4, respectively, which are also far below world level values (20).

\section{Study objectives}

Despite the unequal distribution of health care services and resources across Sudan's regions, up to now it seems that no study has been carried out on the geographic distribution of health resources. Therefore, this study aims to fill the existing research gap by analysing the level of inequality in geographic distribution of the public sector's health resources using 2016 data. In addition, the study also aims to measure the relationships between density of health human resources (physicians and nurse) and health outcomes.

\section{Methods}

\section{Study variables and data sources}

To measure the level of health resources distribution between states, 2 groups of variables were studied:
- health facilities, which includes hospitals, health units, health centres and beds;

- human resources, which includes specialist physicians, dentists, all physicians, nurses, public health officers, medical assistants, technicians, midwives, and health visitors.

The data for this study were obtained from the Sudan Health Statistical Report of 2016, published by the Federal Ministry of Health (16). The report provides detailed health statistics for the 18 states of Sudan for 2016 .

\section{Inequality indices}

There are many indices for measuring inequality in the geographic distribution of health variables. The most common indices used in analysing inequality in the distribution of health resources include the Lorenz curve, the Gini coefficient, the weighted coefficient of variation and the dissimilarity index (21-24). In addition, the author has developed a resource concentration index to determine relatively under- and over-resourced regions/ states.

\section{Weighted coefficient of variation}

Like the ordinary coefficient of variation, weighted coefficient of variation (WCV) is a relative measure of dispersion. Taking the impact of population share in each state into account, the population WCV for a variable y (e.g. health resource), given a sampling weight hw and size variable hs (population size), is defined as (24):

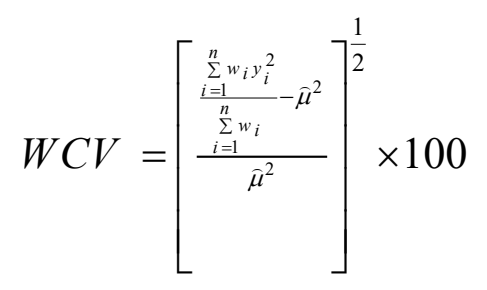

Where:

$$
\mathrm{w}_{\mathrm{i}}=\mathrm{hw}_{\mathrm{i}} \times \mathrm{hs}_{\mathrm{i}} \quad \text { and } \widehat{\mu}=\frac{\sum_{\mathrm{i}=1}^{\mathrm{n}} \mathrm{w}_{\mathrm{i}} \mathrm{y}_{\mathrm{i}}}{\sum_{\mathrm{i}=1}^{\mathrm{n}} \mathrm{w}_{\mathrm{i}}}
$$

High WCV values indicate a higher degree of health resource inequality and vice versa. As a relative measure of dispersion, WCV allows comparison of inequality levels for different health variables.

\section{Gini coefficient}

The Gini coefficient (GC) is widely used to assess the inequality distribution of health resources. For a sample of size $\mathrm{n}$ (e.g. number of regions), the GC for variable y (e.g. health resource) given a sampling weight hw and size variable hs (population size) is estimated as follows (24):

$$
\widehat{I}=1-\frac{\bar{\xi}}{\widehat{\mu}}
$$


Where:

$$
\bar{\xi}=\sum_{\mathrm{i}=1}^{\mathrm{n}}\left[\frac{\mathrm{V}_{\mathrm{i}}^{2}-\mathrm{V}_{\mathrm{i}+1}^{2}}{\mathrm{~V}_{1}^{2}}\right] \mathrm{y}_{\mathrm{i}} ; \mathrm{V}_{\mathrm{i}}=\sum_{\mathrm{k}=\mathrm{i}}^{\mathrm{n}} \mathrm{w}_{\mathrm{k}} ; \mathrm{w}_{\mathrm{k}}=\mathrm{hw}_{\mathrm{k}} \times \mathrm{hs}_{\mathrm{k}} ; \text { and } \mathrm{y}_{1} \geq \mathrm{y}_{2} \geq \ldots \mathrm{y}_{\mathrm{n}-1} \geq \mathrm{y}_{\mathrm{n}}
$$

$$
\widehat{\mu}=\frac{\sum_{i=1}^{\mathrm{n}} \mathrm{w}_{\mathrm{i}} \mathrm{y}_{\mathrm{i}}}{\sum_{\mathrm{i}=1}^{\mathrm{n}} \mathrm{w}_{\mathrm{i}}}
$$

The coefficient value ranges between 0 and 1 . Lower values indicate less inequality in the distribution of the resources, and higher values suggest greater inequality. A Gini coefficient $<0.2$ indicates absolute equality, $0.2-0.3$ low inequality, 0.3-0.4 medium inequality, 0.4-0.5 high inequality and $>0.5$ represents extreme inequality (2527).

\section{Dissimilarity index}

The dissimilarity index (DI), also known as the Hoover Index, measures the proportion of each health resource that would have to be redistributed in order to achieve even distribution of the health resource between states or regions. The index takes the following form (28):

$$
H_{j}=\frac{1}{2} \sum_{i=1}^{n}\left|\frac{p_{i}}{P .}-\frac{y_{i j}}{y_{j}}\right|
$$

Where $\frac{P_{i}}{P}$ is the percentage of the population in region $i$ to the total population in the country, $\frac{y_{i j}}{y_{j}}$ is the percent of resource $j$ in region $i$ to the total resource $j$ in the country. The index value ranges between 0 and 1 ; smaller values indicate greater equity in resource allocation, and larger values show higher inequality in the distribution of the resource.

\section{Lorenz curves}

In addition to GC and DI indices, Lorenz curves (LCs) are widely used to represent graphically the distribution of health resources $(29,30)$. The diagonal line in the LC represents perfect equality of the resource distribution among regions/states. The more the variable of interest curve deviates from the diagonal, the greater the degree of unequal distribution of the variable between regions/states.

\section{Resource concentration index}

To determine the resource concentration among the regions under study, the author developed the following formula:

$$
\mathrm{RC}_{\mathrm{i}}=\frac{\left(\frac{\left.\mathrm{y}_{\mathrm{ij}} / \mathrm{y}_{\mathrm{j}}\right)}{(\mathrm{P} / \mathrm{P})}\right.}{(\mathrm{P})}
$$

The resource concentration index (RCI) determines the source of inequality with a value $\geq$ zero; $\left(R C_{i} \geq 0\right)$.
An index value $=1$ indicates that the percentage of the health resource allocated to the state is exactly equal to the percentage of the population in the region; a value $<1$ means that the region receives relatively fewer health resources compared to its population size, and a value $>1$ shows that the region receives relatively higher health resources compared to its population size.

\section{Data analysis}

The Distribution Analysis Stata Package was used to calculate inequality indices (WCV and GC) and plot Lorenz curves for the health resources variables. Dissimilarity and resource concentration indices were calculated using Excel. Spearman's rho correlation was used to compute the correlation coefficients between density of health human resources (physicians and nurses) and health outcomes (IMR, U5MR, MMR, and life expectancy) using SPSS statistical package. For all the methods used for data analysis, the unit of analysis is the "state", as the health data were aggregated to state level in the Health Statistical Report of 2016.

\section{Results}

\section{Weighted coefficient of variation, Gini coefficient, and dissimilarity index}

Table 1 shows the WCV and GC values for the health resources based on the population size, in addition to DI values. For health facilities, the WCV values show that hospitals beds is the most unequally distributed resource among the 18 states with a value of $82.9 \%$, followed by health units, health centres and hospitals with respective WCV values of $76.6 \%, 66.0 \%$ and $62.8 \%$. For human resources, the WCV values show that the most unequally distributed resources are dentists, specialists, total physicians, technicians and nurses, with extremely high WCV values of $145.0 \%, 129.4 \%, 124.6 \%, 113.9 \%$ and $95.9 \%$ respectively. The inequality distributions of the other human resources are relatively lower, with WCV values ranging between $33.1 \%$ for medical assistants and $75.4 \%$ for public health officers.

The GC values for the health facilities vary from 0.32 for hospitals to 0.43 for beds. Based on the GC interpretation, the inequality distribution of health facilities is medium except for beds, for which the inequality distribution level is high. The GC values for human resources vary considerably, ranging from 0.18 to 0.68 . The GC values for specialists, dentists, total physicians and technicians vary range from 0.53 to 0.68 , showing that the distributions of these resources exhibits extreme levels of inequality. The levels of inequality for nurses and public health officers are high, for midwives and health visitors medium, and for medical assistants very low. 
Figure 1 Lorenz curve for Sudan's health facilities, 2016

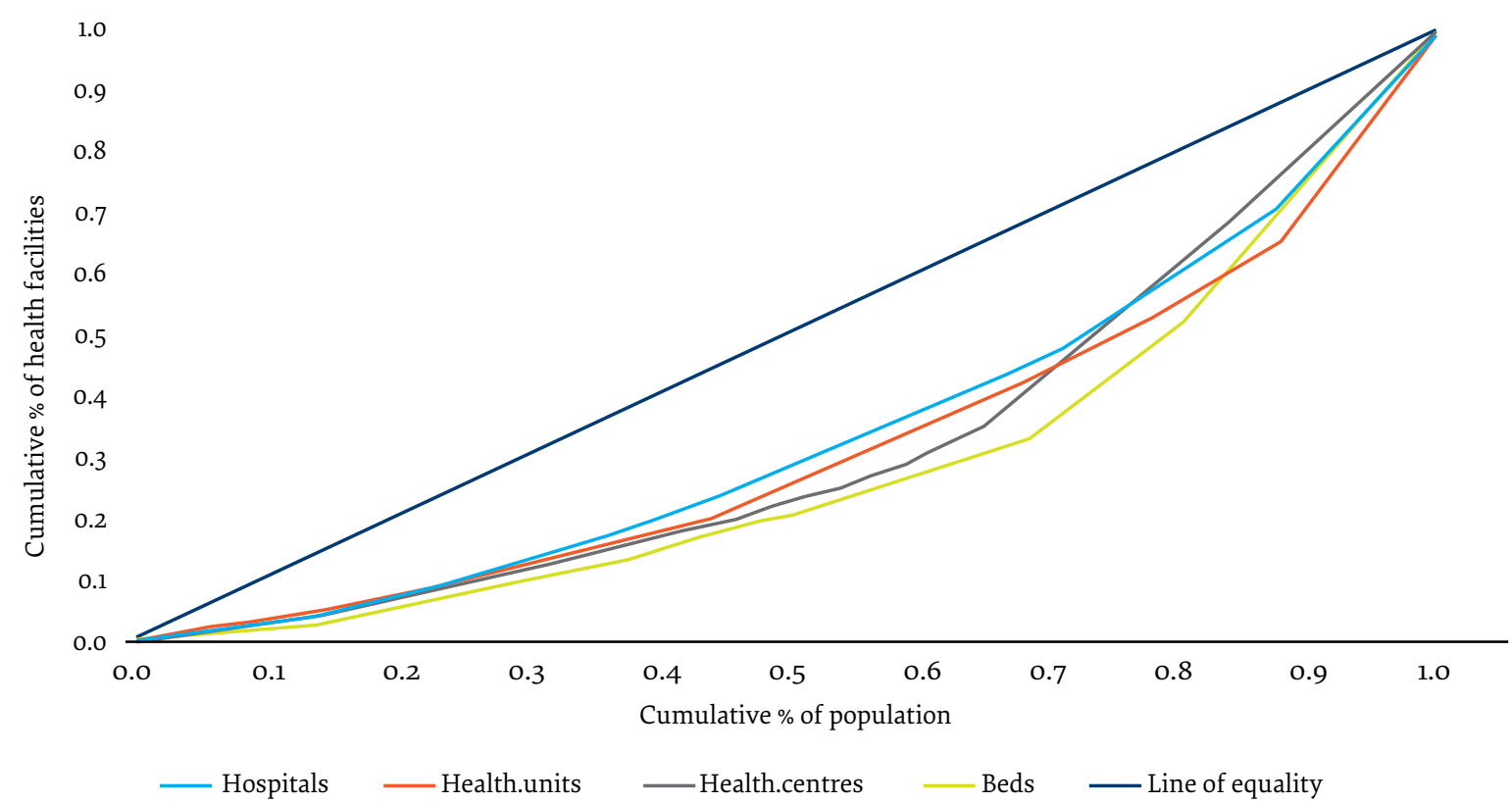

The Lorenz curves depicted in Figure 1 show that distribution of health facilities is unequal, as all the curves were far from the line of equality. The distribution of beds was the worst, followed by health centres, health units and hospitals. For human resources, the geographical distribution is highly unequal, with distribution of specialists, total physicians and dentists worst (Figure 2).

The DI values for health facilities vary from $16.3 \%$ for beds to $27.6 \%$ for health units (Table 1). The DI values for human resources range from $17.8 \%$ for nurses to $44.2 \%$ for dentists. For example, according to the DI values, $44.2 \%$ of

dentists in those states that have more dentists relative to their population size need to be transferred to states that have fewer dentists in order to achieve equal distribution across the states. The interpretation proceeds similarly for the other DI values.

\section{Resource concentration indices}

Tables 2 and 3 show the values of RCI for health facilities and human resources for the 18 states. Based on these values, the states that have more hospitals relative to their populations were Northern, River Nile, Red Sea,

Figure 2 Lorenz curve for Sudan's health human resources, 2016

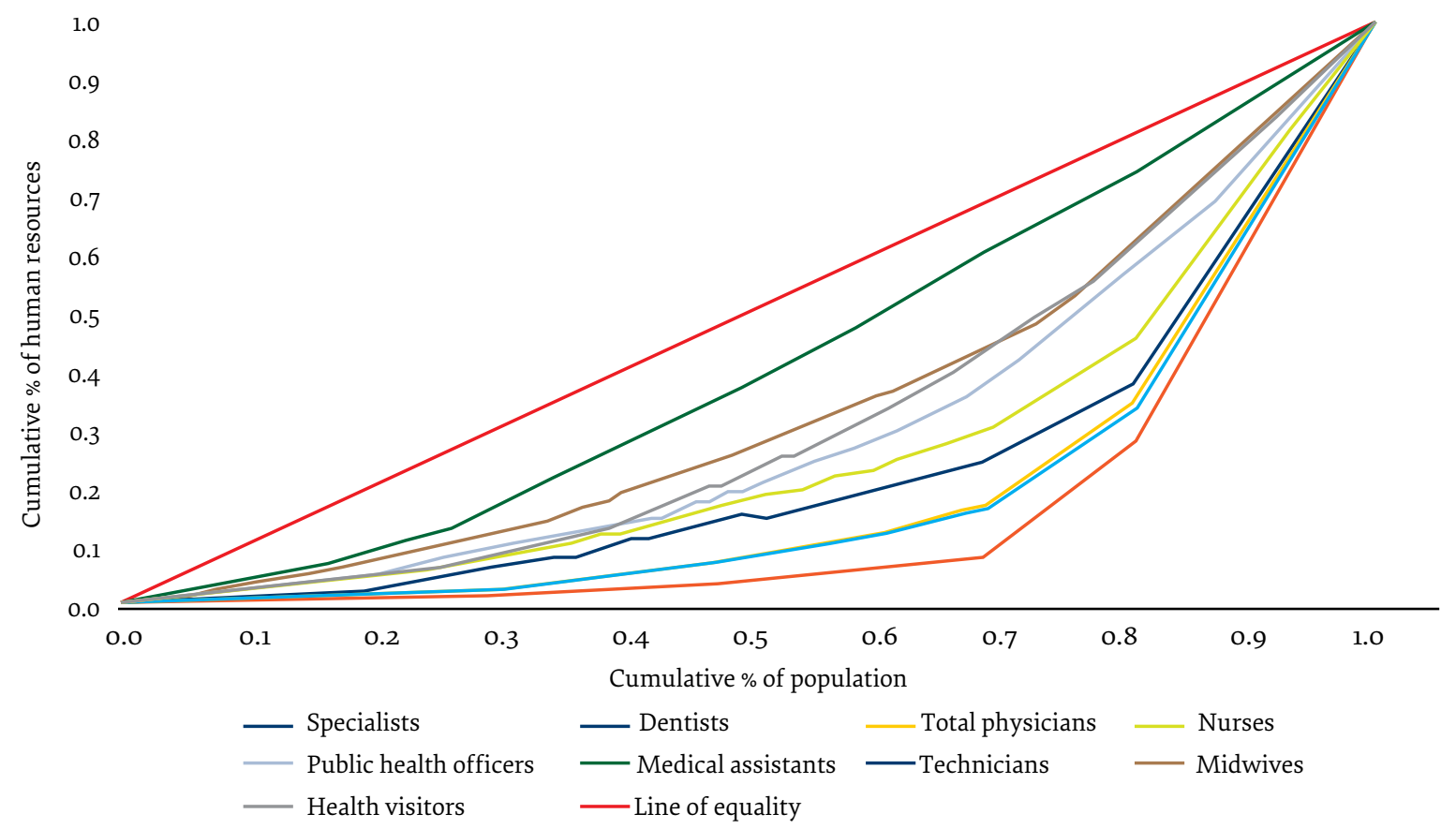




\begin{tabular}{|c|c|c|c|}
\hline Variable & $\begin{array}{c}\text { Weighted coefficient of } \\
\text { variation (\%) }\end{array}$ & Gini coefficient & Dissimilarity index (\%) \\
\hline \multicolumn{4}{|l|}{ Health facilities } \\
\hline Hospitals & 62.8 & 0.32 & 20.1 \\
\hline Health units & 76.6 & 0.37 & 27.6 \\
\hline Health centres & 66.0 & 0.36 & 18.1 \\
\hline Beds & 82.9 & 0.43 & 16.3 \\
\hline \multicolumn{4}{|l|}{ Human resources } \\
\hline Specialists & 129.4 & 0.61 & 30.7 \\
\hline Dentists & 145.0 & 0.68 & 44.2 \\
\hline Total physicians & 124.6 & 0.60 & 29.3 \\
\hline Nurses & 95.9 & 0.47 & 17.8 \\
\hline Public health officers & 75.4 & 0.41 & 21.7 \\
\hline Medical assistants & 33.1 & 0.18 & 21.4 \\
\hline Technicians & 113.9 & 0.53 & 21.2 \\
\hline Midwives & 60.3 & 0.33 & 25.6 \\
\hline Health visitors & 65.5 & 0.37 & 25.6 \\
\hline
\end{tabular}

Gezira and Sinnar. In contrast, Kassala, Khartoum, South Darfur, West Darfur and Eastern Darfur states have fewer hospitals relative to their populations. Regarding other health facilities, South Darfur, Eastern Darfur and Kassala states have the lowest RCI values, signifying the need of more health facilities in these states.

The RCI values for human resources show that number of physicians (specialists, dentists, total physicians) and nurses are relatively higher in Northern, River Nile, Khartoum and Gezira states, as RCI values are greater than one. Conversely, the RCI values for other states, particularly Darfur, Kordofan and Blue Nile states, are much lessr than one, indicating that these states have a relatively low number of physicians and nurses compared with their populations. For allied health personnel (public health officers, medical assistants, technicians, midwives, health visitors), the RCI values show that their distributions are irregular but generally have similar patterns to those of physicians.

\begin{tabular}{|c|c|c|c|c|}
\hline State & Hospitals & Health units & Health centres & Beds \\
\hline Northern & 2.8 & 3.3 & 1.0 & 2.7 \\
\hline River Nile & 1.6 & 0.8 & 3.5 & 2.0 \\
\hline Red Sea & 1.6 & 1.4 & 1.0 & 1.2 \\
\hline Gadaerf & 1.3 & 1.9 & 0.7 & 1.1 \\
\hline Kassala & 0.7 & 0.5 & 0.9 & 0.7 \\
\hline Khartoum & 0.5 & 0.3 & 0.7 & 1.2 \\
\hline Gezira & 1.5 & 1.6 & 1.4 & 1.2 \\
\hline Sinnar & 1.5 & 1.5 & 1.1 & 1.3 \\
\hline White Nile & 1.1 & 1.3 & 1.0 & 0.8 \\
\hline Blue Nile & 1.3 & 1.2 & 1.3 & 1.1 \\
\hline North Kordofan & 1.1 & 1.3 & 1.5 & 0.9 \\
\hline South Kordofan & 0.8 & 1.0 & 0.7 & 0.7 \\
\hline West Kordofan & 0.9 & 0.9 & 1.1 & 0.9 \\
\hline North Darfur & 1.0 & 0.6 & 0.7 & 0.6 \\
\hline South Darfur & 0.4 & 0.2 & 0.4 & 0.4 \\
\hline West Darfur & 0.5 & 0.7 & 1.0 & 0.6 \\
\hline Central Darfur & 0.9 & 2.5 & 1.2 & 0.6 \\
\hline Eastern Darfur & 0.4 & 1.0 & 0.6 & 0.3 \\
\hline
\end{tabular}




\begin{tabular}{|c|c|c|c|c|c|c|c|c|c|}
\hline State & Specialists & Dentists & $\begin{array}{c}\text { Total } \\
\text { physicians }\end{array}$ & Nurses & $\begin{array}{l}\text { health } \\
\text { officers }\end{array}$ & $\begin{array}{c}\text { Medical } \\
\text { assistants }\end{array}$ & Technicians & Midwives & $\begin{array}{c}\text { Health } \\
\text { visitors }\end{array}$ \\
\hline Northern & 1.1 & 1.1 & 1.5 & 2.2 & 1.0 & 4.0 & 1.6 & 1.2 & 0.5 \\
\hline River Nile & 1.3 & 0.7 & 1.5 & 1.4 & 2.0 & 1.9 & 1.5 & 0.8 & 3.9 \\
\hline Red Sea & 1.0 & 0.9 & 0.7 & 1.0 & 1.0 & 0.9 & 0.5 & 0.8 & 0.4 \\
\hline Gadaerf & 0.7 & 0.2 & 0.7 & 1.1 & 1.9 & 0.7 & 1.1 & 0.8 & 0.6 \\
\hline Kassala & 0.7 & 0.4 & 0.8 & 0.9 & 0.5 & 1.1 & 0.7 & 0.8 & 0.3 \\
\hline Khartoum & 2.3 & 2.8 & 2.1 & 1.5 & 0.8 & 0.4 & 1.9 & 0.1 & 0.8 \\
\hline Gezira & 1.5 & 1.9 & 1.4 & 1.1 & 1.7 & 0.6 & 1.0 & 1.0 & 0.9 \\
\hline Sinnar & 0.8 & 0.6 & 1.0 & 1.5 & 0.9 & 2.2 & 1.1 & 1.0 & 0.4 \\
\hline White Nile & 0.6 & 0.6 & 0.9 & 0.8 & 1.2 & 1.1 & 0.8 & 1.0 & 1.2 \\
\hline Blue Nile & 0.3 & 0.4 & 0.9 & 1.4 & 0.4 & 1.3 & 0.8 & 1.7 & 2.9 \\
\hline North Kordofan & 0.6 & 0.2 & 0.5 & 0.6 & 1.1 & 1.1 & 0.7 & 1.8 & 1.2 \\
\hline South Kordofan & 0.2 & 0.1 & 0.3 & 0.6 & 1.4 & 1.2 & 0.3 & 1.1 & 1.7 \\
\hline West Kordofan & 0.6 & 0.5 & 0.5 & 1.0 & 1.2 & 1.3 & 0.5 & 2.0 & 1.7 \\
\hline North Darfur & 0.4 & 0.2 & 0.4 & 1.0 & 0.7 & 1.4 & 0.8 & 1.7 & 1.6 \\
\hline South Darfur & 0.2 & 0.1 & 0.1 & 0.3 & 0.4 & 0.8 & 0.5 & 0.5 & 0.5 \\
\hline West Darfur & 0.5 & 0.2 & 0.3 & 0.4 & 0.1 & 0.8 & 0.8 & 4.6 & 0.8 \\
\hline Central Darfur & 0.3 & 0.3 & 0.2 & 0.2 & 0.1 & 0.4 & 0.1 & 1.9 & 0.5 \\
\hline Eastern Darfur & 0.2 & 0.0 & 0.4 & 0.2 & 0.9 & 0.6 & 0.2 & 1.0 & 0.3 \\
\hline
\end{tabular}

\section{Why equality of health resources distribution matters?}

To answer this point, correlation analysis using Spearman's rho correlation was performed to examine the relationship between density of human resources (physicians and nurses) and health outcomes, represented by IMR, U5MR, MMR and life expectancy.

The results of Spearman's correlation show there is a significant positive correlation between physician density and life expectancy $(P<0.001)$, revealing that the states with higher physician density have longer life expectancy (Table 4). The results also show that there are significant negative correlations between physician density and IMR, U5MR and MMR ( $P<0.05$ for all). This indicates that the states with higher physician density have lower IMR, U5MR and MMR. Moreover, there are significant negative correlations between nurse density and $\mathrm{U}_{5} \mathrm{M}$ and MMR at the 0.05 level of significance, indicating that states with a high density for nurses have lower $\mathrm{U}_{5} \mathrm{M}$ and MMR. However, there is no satisfactory evidence of a statistically significant relationship between nurse density and life expectancy and U5M $(P>0.05)$.

The overall results signify the importance of equal allocation of health human resources between the states in increasing access to health care services and enhancing health outcomes.

\section{Discussion}

Over the past few decades, the government of Sudan has adopted a number of policies and measures aimed at providing equitable, accessible and affordable quality health care services. Key policies and measures include interstate and intrastate redistribution of health human resources, improving working conditions, provision of financial incentives and overseas training for health workers in rural areas (31).

Despite the measures taken to improve health status and reduce health inequalities, the study results show

Table 4 Spearman's correlations matrix between density of physicians and nurses, life expectancy, infant mortality rate (IMR), under-5 years mortality rate (U5MR) and maternal mortality rate (MMR) for the 18 states in Sudan, 2016

\begin{tabular}{lccccc} 
Variable & $\begin{array}{c}\text { Density of } \\
\text { Physicians }\end{array}$ & $\begin{array}{c}\text { Density of } \\
\text { nurses }\end{array}$ & Life expectancy & IMR & U5MR \\
Density of nurses & $0.847^{* * *}$ & & & & \\
Life expectancy & $0.765^{* * *}$ & 0.522 & & & \\
IMR & $-0.658^{* *}$ & $-0.572^{*}$ & -0.449 & & \\
U5MR & $-0.625^{*}$ & -0.486 & $-0.645^{*}$ & $0.762^{* * *}$ & 0.329 \\
MMR & $-0.732^{* *}$ & $-0.646^{* *}$ & $-0.687^{* *}$ & 0.383 & \\
\hline
\end{tabular}


that the distributions of health resources were highly asymmetric, demonstrating substantial disparities among Sudan's 18 states. Based on GC values, the inequalities in the distribution of health facilities ranged from moderate to high. Vis-à-vis human resources, the inequality was very high for physicians (specialists, dentists, total physicians) and varied from low to very high for allied health personnel. To achieve equal distribution of health resources among Sudan's states, the study results show that $16-28 \%$ of the health facilities and 18 $44 \%$ of the human resources need redistribution between regions. Furthermore, the findings strongly confirm the importance of equal geographical distribution of human resources between the regions as there were significant positive relationships between density of human resources and health outcomes.

The unequal distribution of health resources is a part of the macro-level problem of uneven development and maldistribution of wealth in Sudan. Moreover, the problem of uneven development is the main cause of the current political conflict between the government and the armed movements in Darfur, Kordofan and Blue Nile states and the non-ruling political parties $(10,11)$.

The results of this study are consistent with the findings of some studies carried out in other developing countries. For example, Rabbanikhah et al. found that the distribution of general practitioners among Iran's provinces during 2010-2016 were unequal (2): GC values ranged between 0.272 and 0.356 . Geographic inequalities in the distribution of health care services and health outcomes were also reported in Ethiopia in 2011: GC values ranged from 0.047 for under-five deaths to 0.33 for skilled birth attendance (32). In China, Yang assessed the distribution of health resources during 2004-2009 and concluded that inequalities in health care were pervasive and favoured urban population (33). Regional inequalities in health care services and health outcomes have also been reported in Tunisia and Morocco $(34,35)$.

However, the results of this study did not agree with some studies in other developing countries. For example, in Saudi Arabia, El-Farouk et al. found that health resources were equitably distributed among the administrative regions (36). Similarly, in Mongolia, Erdenee et al. found that the distributions of health care resources based on population in 2014 were adequate, but the distributions of these resources when based on geographic area were unequal (37). Additionally, research carried out by Wiseman et al. showed that the distribution of physicians based on population at the provincial level in Fiji in 2007 was relatively equal (38).

The results of the correlation analysis show that in general the Sudanese states with a greater density of human health resources have higher life expectancy and lower mortality rates, represented by the IMR, U5MR and MMR. These results are consistent with the results of a number of previous studies investigating the link between human resources for health and health outcomes $(39,40)$. Moreover, a great deal of research has found that unequal distribution of health resources has negative effects on access to health care services and, hence, on health-related outcomes (41).

\section{Limitations and future research}

State-level data obtained from the annual health statistical report of 2016 were used to describe and analyse the regional differences in health resources in Sudan. It would be interesting to perform further analyses on the geographical distribution health resources within each state to compare inter and intra-state distribution.

Furthermore, the data used were also aggregated at the variables level. The annual health report lacks detailed information on health facilities such as rural and tertiary hospitals, which provide different levels of health care services. The availability of detailed data on health variables would improve the level analysis and the results.

Based on the study findings and data restrictions, further research considering inter-state distribution of health resources and disaggregated health variables is highly recommended.

\section{Conclusion}

There are distinct regional disparities in health resources in Sudan. Furthermore, it is also established that in the states with relatively better health resources, the populations have longer life expectancy and lower mortality rates. In contrast, the populations in relatively under-resourced states have shorter life expectancy and higher mortality rates.

Based on these findings, the need to address the problem of disproportionate distribution of health resources, particularly human resources, is immensely important. Therefore, we recommend the following:

- There is a crucial need to improve health status in the relatively under-resourced states, particularly Darfur, South Kordofan and Blue Nile states.

- In future health strategies, there is a need to use resource allocation models that take into account the population size and health outcome variables in each state.

- There is a need for the allocation of more funds for the health sector to implement equity-promoting strategies.

- Improving working conditions and offering greater incentives are important to attract, motivate and retain health workers in rural areas, particularly in Darfur and Kordofan states.

Funding: None.

Competing interests: None declared. 


\section{Disparités régionales dans la répartition des ressources sanitaires du Soudan \\ Résumé}

Contexte : La répartition égale des ressources sanitaires est un objectif central des plans stratégiques à long et moyen terme pour le secteur de la santé au Soudan. Cependant, les cibles de ces plans n'ont pas encore été atteintes, ce qui se traduit par une faible performance du système de santé dans son ensemble. La répartition inégale des ressources sanitaires a entraîné d'importantes disparités régionales en matière de prestation de services de santé.

Objectifs : La présente étude vise à décrire et à analyser l'inégalité dans la répartition géographique des ressources sanitaires physiques et humaines du secteur public au Soudan. En outre, l'étude vise également à mesurer les relations entre la densité des ressources de santé et les résultats sanitaires.

Méthodes : Les données sur les ressources sanitaires et les résultats sanitaires au niveau des États obtenues à partir du Rapport sur les statistiques sanitaires du Soudan de 2016 ont été utilisées pour calculer des indices d'inégalité, tracer des courbes de Lorenz et calculer l'analyse de corrélation de Spearman entre la densité des ressources sanitaires et les résultats sanitaires.

Résultats : Nos résultats montrent que la répartition des ressources sanitaires, basée sur la taille de la population, était très inégale entre les 18 États du Soudan.

Conclusion: Il faut absolument améliorer la situation sanitaire dans les États qui disposent de ressources relativement insuffisantes, en particulier dans les États du Darfour, du Kordofan du Sud et du Nil bleu. En outre, le gouvernement doit utiliser des modèles d'allocation des ressources sanitaires qui tiennent compte de la taille de la population et des variables des résultats sanitaires dans chaque État dans les stratégies futures de santé.

$$
\begin{aligned}
& \text { التفاوتات الإقليمية في توزيع الموارد الصحية في السودان } \\
& \text { محمد إسماعيل } \\
& \text { الخلاصة }
\end{aligned}
$$

الخلفية: ظل التوزيع المتكافئ للموارد الصحية هدفًا أساسيًا لكل من الخطط الاستر اتيجية طويلة الأمد ومتوسطة الأمد للقطاع الصحي في الحئ السودان.

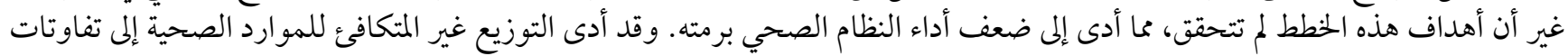

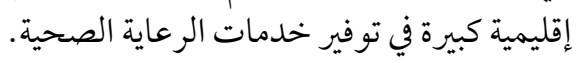

الأهداف: هدفت هذه الدراسة إلى وصف عدم المساواة وتحليلها في التوزيع الجلغرافي للموارد الصحية المادية والبشرية للقطاع العام في السودان.

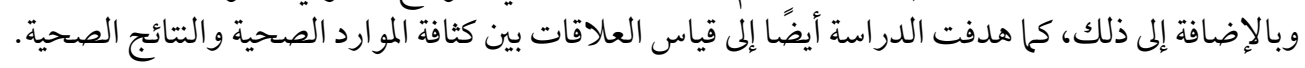

طرق البحث: استخدمت البيانات على مستوى الدولة بشأن الموارد الصحية والمخرجات الصحية التي جمعت من التقرير الإحصائي للصحة

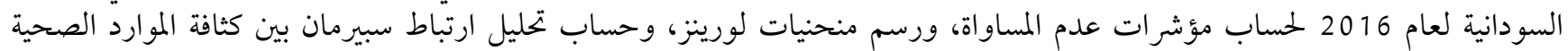
والمخرجات ذات الصلة بالصحة.

النتائج: تبين النتائج التي توصلنا إليها أن توزيع الموارد الصحية، على أساس حجم السكان، كان غير متكافئ إلى حد كبير بين ولايات السودان البالغ عددها 18 ولاية.

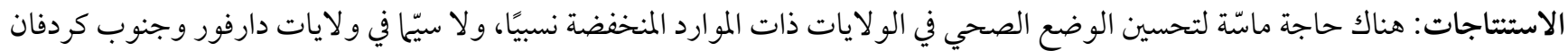

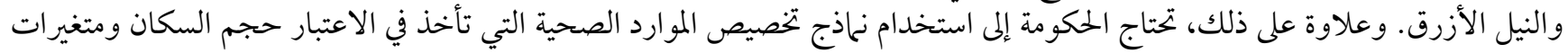

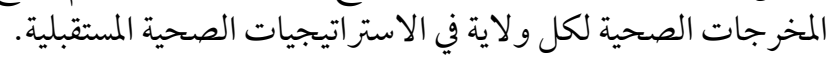

\section{References}

1. Zarrabi A, Shaykh Baygloo R. Classification of provinces of Iran by health indicators. Social Welfare Quarterly. 2011;11(42):107-28.

2. Rabbanikhah F, Moradi R, Mazaheri E, Shahbazi S, Barzegar L, Karyani, AK. Trends of geographic distribution of general practitioners in the public health sector of Iran. J Educ Health Promot. 2018 Jul 6;7:89. doi:10.4103/jehp.jehp_14_18

3. Ahmed Kiadaliri A, Najafi B, Haghparast-Bidgoli H. Geographic distribution of need and access to health care in rural population: an ecological study in Iran. Int J Equity Health. 2011 Sep 22;10:39. doi:10.1186/1475-9276-10-39

4. Hanson K, Ranson K, Oliveira-Cruz V, Mills A. Expanding access to priority health interventions: a framework for understanding the constraints to scaling-up. J Int Dev. 2003;15:1-14.

5. Maddox PJ. Administrative ethics and the allocation of scarce resources. J Issues Nurs. 1998(102):4-6. 
6. Shi L, Starfield B, Kennedy B, Kawachi I. Income inequality, primary care, and health indicators. J Fam Pract. 1999;48(4):275-84. PMID:10229252

7. Van Deurzen I, Van Oorschot W, Van Ingen E. The link between inequality and population health in low and middle-income countries: policy myth or social reality? PLoS ONE. 2014;9(12):e115109. doi:10.1371/journal.pone.0115109

8. Sudan health sector fact sheet. Geneva: World Health Organization; 2013 (http://www.who.int/hac/sudan_healthsector_factsheet.pdf, accessed 8 March 2020).

9. Atser J and Akpan PA. Spatial distribution and accessibility of health facilities in Akwa Ibom State, Nigeria. Ethiopian J Environ Studies Manage. 2009;2:49-57.

10. Sudan: Conflict analysis and options for systemic conflict transformation: a northern and a southern view. Berlin: Berghof Foundation for Peace Support; 2006.

11. Daw Elbiet, MS. Uneven development and conflict in Sudan a case study of North Darfur State [thesis]. Khartoum: University of Khartoum; 2007.

12. 25-year strategic plan for health sector. Khartoum: Federal Ministry of Health; 2003.

13. National health sector strategic plan II (2012-16). Khartoum: Federal Ministry of Health; 2012.

14. Health system profile: Sudan. Geneva: World Health Organization; 2006 (http://apps.who.int/medicinedocs/documents/s17310e/ s17310e.pdf, accessed 8 March 2020).

15. El-Battahani, AE and Gadkarim, HA. Governance and fiscal federalism in Sudan, 1989-2015: exploring political and intergovernmental fiscal relations in an unstable polity. Bergen: Chr. Michelsen Institute; 2017 (Sudan Report:1).

16. Annual statistical report. Khartoum. Federal Ministry of Health; 2016.

17. Framework for health information systems and core indicators for monitoring health situation and health system performance. Cairo: World Health Organization Region for the Eastern Mediterranean; 2017 (http://applications.emro.who.int/docs/EMROPUB_2017_EN_16766.pdf?ua=1, accessed 8 March 2020).

18. Achieving the health-related MDGs: it takes a workforce. Geneva: World Health Organization; 2010 (https://www.who.int/hrh/ workforce_mdgs/en/, accessed 8 March 2020).

19. Ismail MA. Technical efficiency of Sudan's health institutions: a state-level analysis. Sudanese J Public Health. 2010;5(3):122-9.

20. Domestic general government health expenditure (\% of GDP). Washington DC: World Bank; 2016 (https://data.worldbank.org/ indicator/SH.XPD.GHED.GD.ZS, accessed 21 March 2020).

21. Ahmad Kiadaliri A, Najafi B, Haghparast-Bidgoli H. Geographic distribution of need and access to health care in rural population: an ecological study in Iran. Int J Equity Health. 2011;10(1):39. PMID:21939511

22. Theodorakis PN, Mantzavinis GD, Rrumbullaku L, Lionis C, Trell E. Measuring health inequalities in Albania: a focus on the distribution of general practitioners. Hum Resource Health. 2006;4(1):5. PMID:16504028

23. Chang RKR, Halfon N. Geographic distribution of pediatricians in the United States: an analysis of the fifty states and Washington, DC. Pediatrics. 1997 Aug;100(2 Pt 1):172-9. PMID:9240795

24. Araar, A and Duclos, JY. DASP: Distributive analysis STATA package. Washington: World Bank, UNDP and Université Laval; 2007.

25. Lin Y, Zhang Q, Chen W, Ling L. The social income inequality, social integration and health status of internal migrants in China. Int J Equity Health. 2017;16(1):1-11.

26. Chen R, Zhao Y, Du J, Wu T, Huang Y, Guo A. Health workforce equity in urban community health service of China. PLoS ONE. 2014;9(12):e115988. https://doi.org/10.1371/journal.pone.0115988.

27. Teng F, He J, Pan X, Zhang C. Metric of carbon equity: carbon Gini index based on historical cumulative emission per capita. Adv Climate Change Res. 2011;2(3):134-40.

28. Nijkamp P, Poot J, Bakens J, eds. The economics of cultural diversity. Cheltenham: Edward Elgar Publishing; 2015.

29. Corrreia I, Veiga P. Geographic distribution of physicians in Portugal. Eur J Health Econ. 2010 Aug;11(4):383-93. doi:10.1007/ s10198-009-0208-8.

30. Theodorakis PN, Mantzavinis GD, Rrumbullaku L, Lionis C, Trell E. Measuring health inequalities in Albania: a focus on the distribution of general practitioners. Human Res Health. 2006;4(1):5-10. doi:10.1186/1478-4491-4-5

31. National human resources for health: strategic plan for Sudan, 2012-2016. Khartoum: Government of Sudan; 2019.

32. Skaftun EK, Ali M, Norheim OF. Understanding inequalities in child health in Ethiopia: health achievements are improving in the period 2000-2011. PLoS One. 2014 Aug 28;9(8):e106460. doi: 10.1371/journal.pone.0106460

33. Yang W. An analysis of inequities and inefficiencies in health and healthcare in China. [thesis]. London: London School of Economics; 2013

34. Boutayeb A. Social inequalities and health inequity in Morocco. Int J Equity Health. 2006;5:1. PMID:16522204

35. What policies should be implemented to address inequalities in health care in Tunisia? Economic Brief. Abidjan: African Development Bank; 2014. 
36. El-Faroukl. Geographical distribution of health resources in the Kingdom of Saudi Arabia: is it equitable? Egypt J Environ Change. 2016;8(2):5-19. doi:10.12816/0038449

37. Erdenee O, Paramita SA, Yamazaki C, Koyama H. Distribution of health care resources in Mongolia using the Gini coefficient. Human Res Health. 2017;15:56. doi:10.1186/s12960-017-0232-1

38. WisemanV, Lagarde M, Batura N, Irava W, Roberts G. Measuring inequalities in the distribution of the Fiji health workforce. Int J Equity Health, 2017;16:115. doi:10.1186/s12939-017-0575-1

39. Anand S, Barnighausen T. Human resources and health outcomes cross-country econometric study. Lancet. 2004;264:1603-9. doi:10.1016/So140-6736(04)17313-

40. Robinson J, Wharrad H. Invisible nursing: exploring health outcomes at a global level-relationships between infant and under-5 mortality rates and the distribution of health professionals, GNP per capita, and female literacy. J Adv Nurs. 2000;32:28-40. doi:10.1046/j.1365-2648.2000.01458.x

41. Speybroeck N, Kinfu Y, Dal Poz MR, Evans DB. Reassessing the relationship between human resources for health, intervention coverage and health outcomes. Background paper prepared for the World Health Report. Geneva: World Health Organization; 2006. 